\title{
The Business Intelligence Based Business Process Management Challenge
}

\author{
Oliver KOPF ${ }^{1}$, Daniel HOMOCIANU ${ }^{2}$ \\ ${ }^{1}$ University of Liechtenstein, Vaduz, Institute of Information Systems \\ 2"Alexandru Ioan Cuza" University of Iasi, Faculty of Economics and Business \\ Administration, Department for Research \\ oliver.kopf@uni.li, daniel.homocianu@feaa.uaic.ro
}

The present paper is trying to bring some solid arguments concerning the common part, the relation and a few limitations when trying to bring together two recent fields of interest, namely Business Intelligence and Business Process Management. The approach is new only in terms of number and combination of reasons and the references are meant to support our ideas when trying to explain certain features. The entire content of the paper is based on putting together relevant theoretical ideas from the literature and some conclusions derived from the experience of authors and other industry representatives with different kinds of technologies and tools with many applications in these fields.

Keywords: Decision Support Systems, Business Intelligence, Business Process Management

\section{Introduction}

One of the main topics of this study is Business Intelligence (BI) considered by Gartner [1] as an umbrella term that includes the applications, infrastructure and tools, and best practices that enable access to and analysis of information to improve and optimize decisions and performance. Based on the Latin word „intellegere" meaning collection and preparation of information and acquired findings [2] or to come to know, see into, perceive, understand, discern, comprehend, gather [3], the term ,intelligence” is coupled with ,business" meaning [4] an organization or economic system where goods and services are exchanged for one another or for money, dealing with concepts as investment, employees, customers and profit. In fact this Latin verb interconnects all the categories of the human mind's content, as identified by Russel Ackof [5] (data to information, knowledge and wisdom by understanding relations, patterns and principles) and this is why we must consider another term intensively used by Peter Drucker [6], namely that of knowledge worker, in order to fully understand what BI is all about [7].

Another major topic of this paper is Business
Process Management which is abbreviated as BPM. According to Dan Power (guru in Decision Support Systems and Business Intelligence) [8], BPM means using a specialized information system to improve business processes such as planning and forecasting to help managers define, measure and manage performance against strategic goals. Management translates goals into key performance indicators (KPI's) that are monitored using computerized systems. A computer-based dashboard is a BPM or Corporate Performance Management (CPM) tool.

According to Gartner [9], BPM is a discipline that treats business processes as assets that directly contribute to enterprise performance by driving operational excellence and business agility. A simple definition of a business process [10] is that of a set of activities performed by an organization to achieve a certain goal. And this recalls two different concepts: that of effectiveness as ratio between the amount of the actual result and the amount of the proposed one and the concept of efficiency usually defined as ratio between expenses and revenue [11]. 


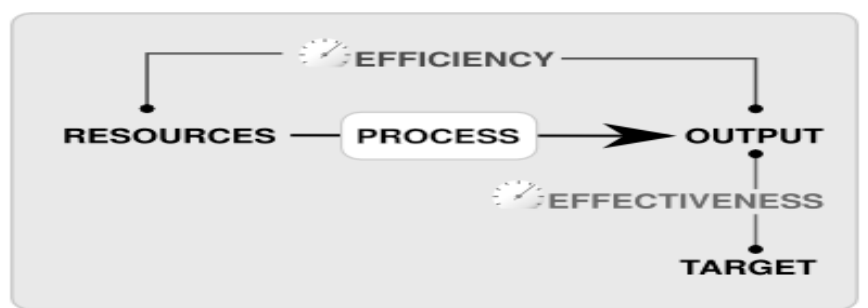

Fig. 1. Effectiveness vs efficiency [12]

Both concepts (fig.1) are widely used in management and know as difficult to optimize in the same time, a good compromise often being recommended [13].

\section{Methodology}

The starting point of this paper was a research of the topic Business Intelligence and the topic Business Process Management separately. After getting a basic understanding for both

fundamental terms we were searching for books, journals and papers considering the relation of both topics. The next step was to find the historical process related to the topic, the current status, some examples and the future expectations.

\section{Definitions, Requirements, Benefits And Progresses in DSS and BI}

DSS represents an older term than BI. It was firstly used in 1971 by Gorry and Scott-Morton [14]. They argued that Management Information Systems primarily focused on structured decisions and suggested that the supporting information systems for semi structured and unstructured decisions should be termed Decision Support Systems [15].

In 1992, the ACS (Australian Computer Society) suggestively presented the location of DSS, at the intersection of Computer Science, Information Systems and Commerce and Business Administration (Figure 2).

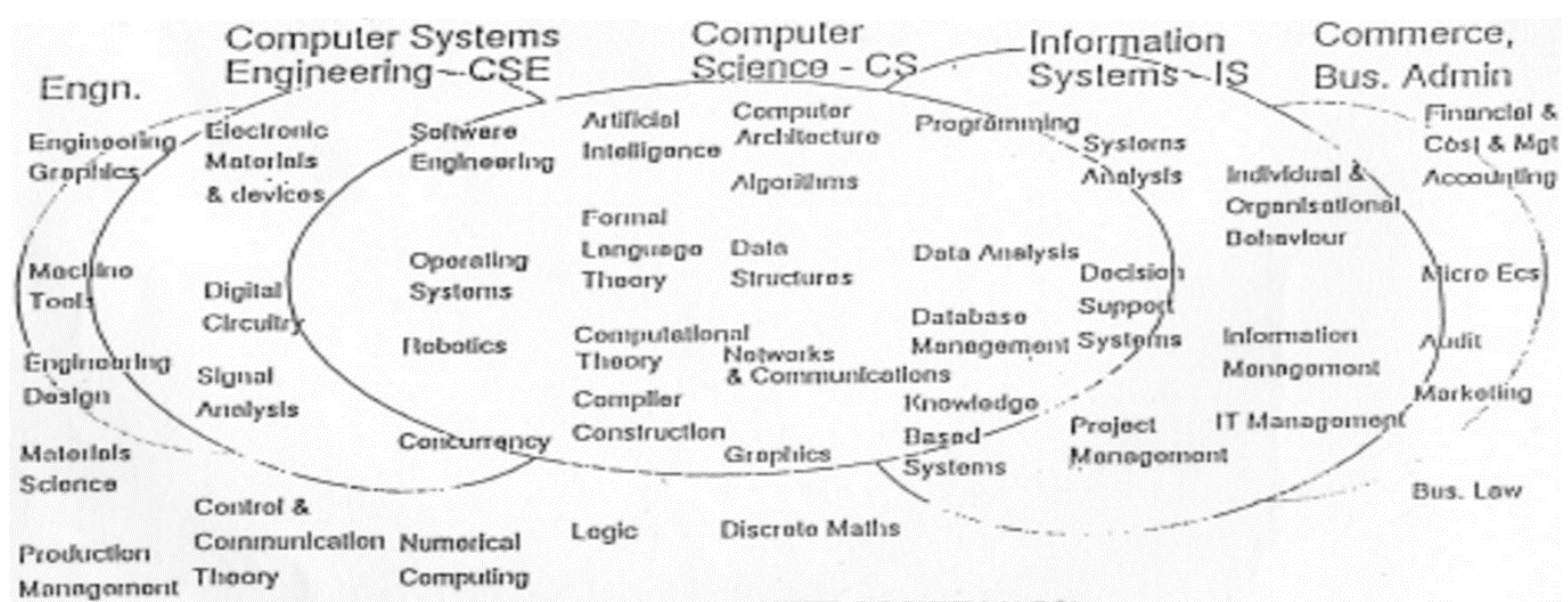

Fig. 2. Model showing information technology areas and disciplines and interfaces with other professional bodies [16]

Techtarget.COM defines a Decision Support System [17] as a computer program application that analyzes business data and presents it so that users can make business decisions more

easily. It is an informational application (in distinction to an operational application that collects the data in the course of normal business operation). A Decision Support System may present information graphically and may include an expert system or artificial intelligence (AI). It may be aimed at business executives or some other group of knowledge workers.

In 2005, Arnott and Pervan made a critical analysis of DSS research, presenting even a short

evolution schema (Figure 3) of the DSS field. 


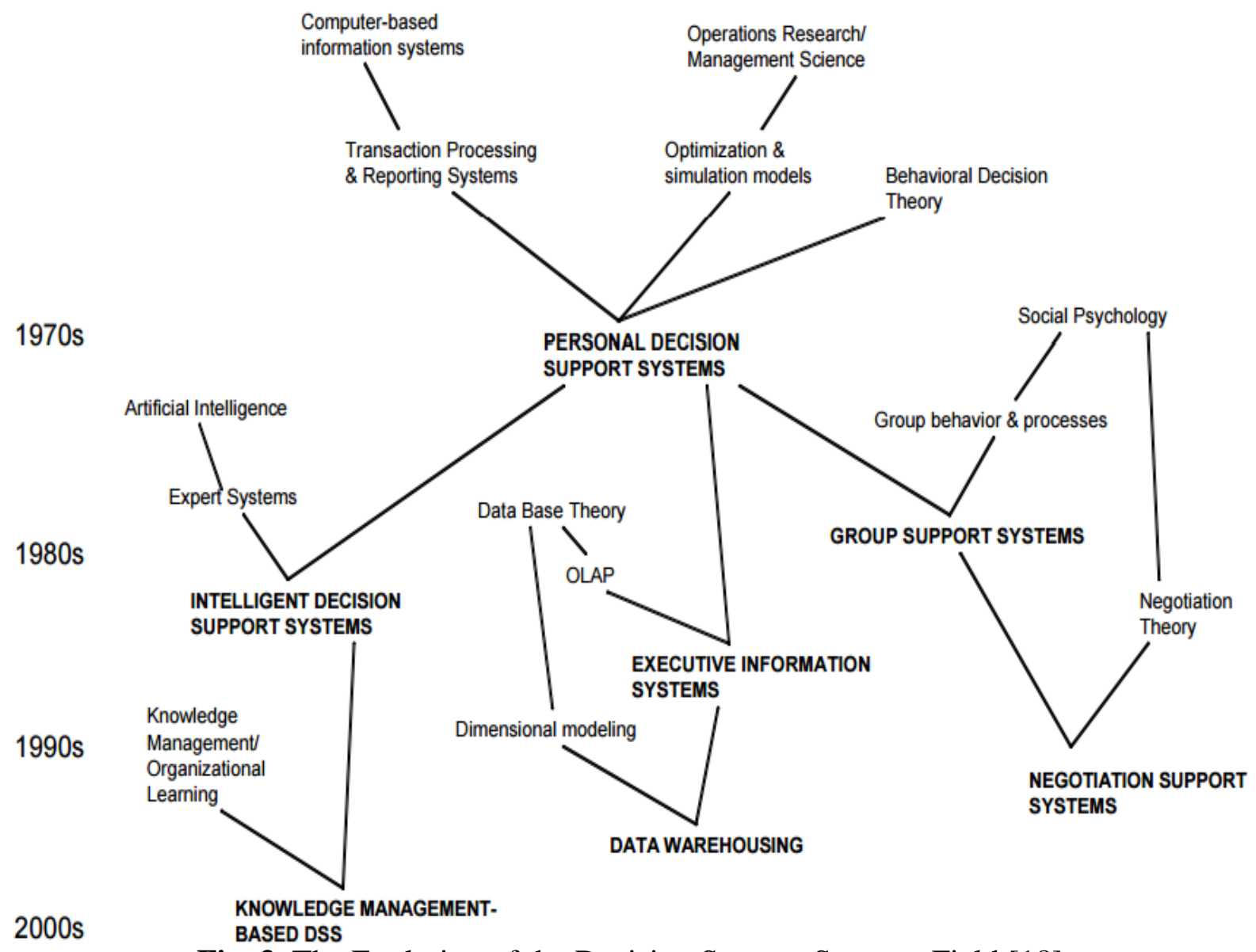

Fig. 3. The Evolution of the Decision Support Systems Field [18]

The BI term was coined by Howard Dresner in 1989. So it is a younger one being defined when the software industry was mired in acronyms like DSS and EIS (Executive Information Systems) while seeking a term that would elevate the debate and better define the analysis of quantitative information by a wide variety of users [19].

According to Dan Power [20] BI describes a set of concepts and methods to improve business decision making by using fact-based support systems. BI is sometimes used interchangeably with briefing books, report and query tools and Executive Information Systems.

Business

Intelligence systems are data-driven DSS.

The BI term appears 3 years before the concept of Balanced Scorecard-BSC (1992, Robert Kaplan - Harvard Business School \& David Norton [21]) that introduces the idea of KPI (Key Performance Indicator), Eficiency, Effectiveness and of an enabler for executives to execute their strategies.
Prior to the BI environment, the first-generation decision support system was widely used. This consisted of an arrangement of computerized tools [22] used to assist managerial decision making. A DSS is generally narrower in scope (initially only used by a few managers within an organization) than BI. Through the advancement of technology the applications of DSS and the access of users grew, expanding the usefulness of DSS and leading to further

evolution into the realm of the more agile [23] BI systems.

Research and case studies provide evidence that a well-designed and appropriate computerized decision support system can encourage fact-based decisions, improve decision quality, and improve the efficiency and effectiveness of decision processes. Decision makers tend to place the greatest attention on more recent information and either ignore or forget

historical information [24] which it is not always good taking into account that these are 
continously hiding identifiable trends, associations and other patterns.

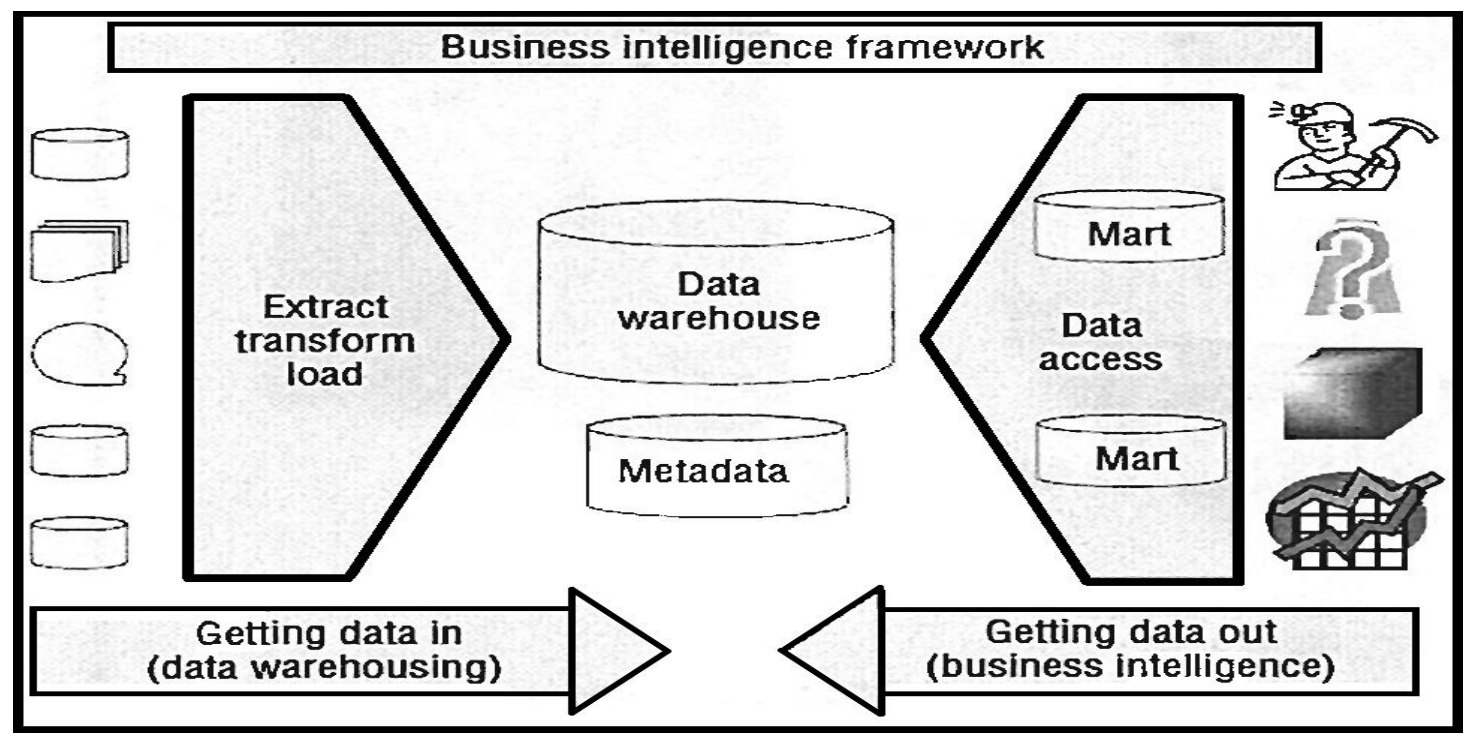

Fig. 4. The BI framework [25]

Chaudhuri et al. (2011) stated [26] that data integrating, cleansing and standardizing data in preparation for BI tasks can be very challenging but efficient data loading is imperative (see the left part of Figure 4).

\section{OLAP}

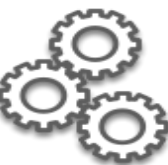

Applications
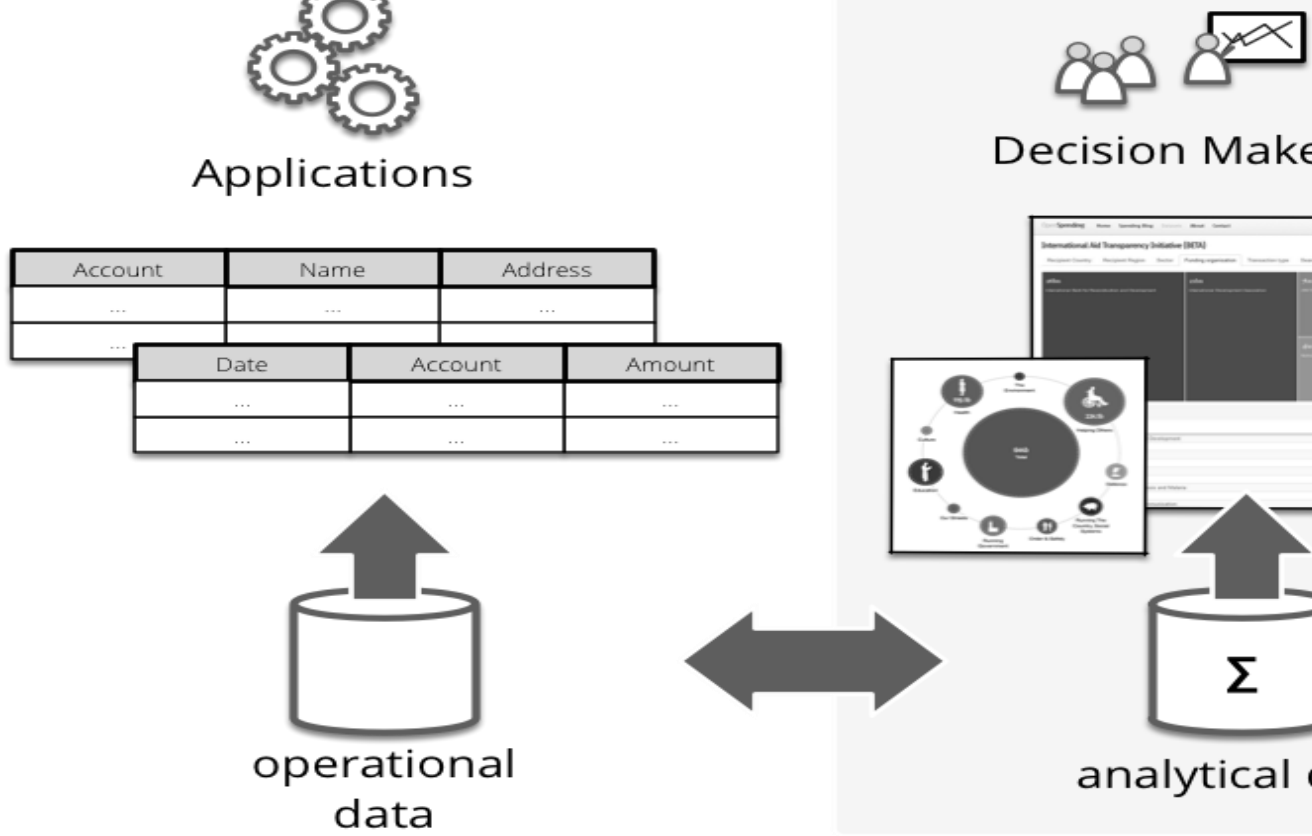

Decision Makers

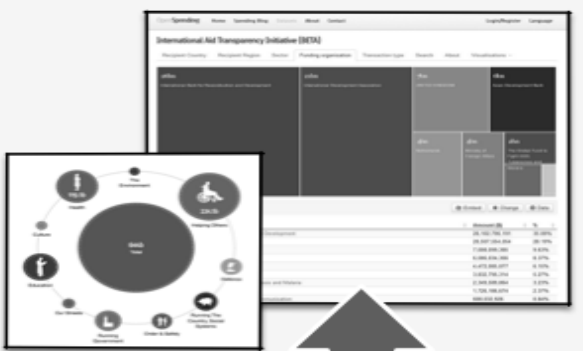

$\Sigma$

analytical data

Fig. 5. Operational (OLTP environments) vs. analytical data (OLAP) [27]

Moreover, a reasonable speed of the interface showing analytical views of data based on pre-aggregations / pre-calculations is vital when using OLAP tools - e.g. the average amount (Figures 5 and 7) displayed at the intersection of two analysis perspectives: Location as an hierarchy (country / state_province / city / 
street / street_no) extracted (example shown at the top of fig.6) from the Adress field and represented on the $1^{\text {st }}$ axis $(\mathrm{OY} /$ rows - Figure 7$)$ / day) extracted (example at the bottom of Figure 6) from the Date field and represented on and Time as an hierarchy (year / month / week the $2^{\text {nd }}$ axis $(\mathrm{OX} /$ columns - Figure 7$)$.

\begin{tabular}{|c|c|c|c|c|}
\hline \multirow[b]{2}{*}{ C } & \multirow{2}{*}{$\begin{array}{l}\text { Text to Columns } \\
\text { Split a single column of text into } \\
\text { multiple columns. }\end{array}$} & \multirow[b]{2}{*}{$\mathrm{F}$} & \multirow[b]{2}{*}{ G } & \multirow[b]{2}{*}{$\mathrm{H}$} \\
\hline & & & & \\
\hline Address & \multirow{3}{*}{$\begin{array}{l}\text { For example, you can separate a } \\
\text { column of full names into separate } \\
\text { first and last name columns. }\end{array}$} & city & street & street_no \\
\hline Mexico, Oaxaca, Tlaxiaco, Bailey Road, 2433 & & aco & Bailey Road & 2433 \\
\hline Canada, BC, Sooke, Dewing Avenue, 2219 & & e & Dewing Avenue & 2219 \\
\hline USA, WA, Issaquah, First Ave. , 7640 & \multirow{3}{*}{$\begin{array}{l}\text { You can choose how to split it up: } \\
\text { fixed width or split at each comma, } \\
\text { period, or other character. }\end{array}$} & uah & First Ave. & 7640 \\
\hline Canada, BC, Burnaby, Tosca Way, 337 & & aby & Tosca Way & 337 \\
\hline USA, CA, Novato, Via Neruda, 8668 & & to & Via Neruda & 8668 \\
\hline USA, WA, Lynnwood, Stillman Court, 1619 & \multirow{2}{*}{ ? Tell me more } & wood & Stillman Court & 1619 \\
\hline Mexico, Oaxaca, Tlaxiaco, D Mt. Hood Circle, 2860 & & .aco & D Mt. Hood Circle & 2860 \\
\hline Mexico, DF, San Andres, Brodia Court, 6064 & Mexico & Andres & Brodia Court & 6064 \\
\hline
\end{tabular}

\begin{tabular}{|c|c|c|c|c|c|c|c|}
\hline 12 & - & $x$ & $\checkmark$ & $=\mathrm{YE}$ & $R(12)$ & & \\
\hline 4 & 1 & & $J$ & K & L & $M$ & N \\
\hline 1 & Date & & Year & Month & Week & Day & Ammount \\
\hline 2 & & 1-Sep-91 & 1991 & 9 & 37 & 10 & 300 \\
\hline 3 & & -Mar-93 & 1993 & 3 & 11 & 11 & 1010 \\
\hline 4 & & 1-Jun-91 & 1991 & 6 & 24 & 11 & 210 \\
\hline 5 & & -May-94 & 1994 & 5 & 21 & 21 & 920 \\
\hline
\end{tabular}

Fig. 6. Simple example of generating (Microsoft Excel) source fields for two hyerarchies behind two analysis dimensions (Location of the customer and Time of account opening)

\begin{tabular}{|c|c|c|c|c|c|c|c|c|c|c|c|c|}
\hline & A & B & $\mathrm{C}$ & D & $\mathbf{E}$ & $\mathrm{F}$ & $G$ & $\mathrm{H}$ & 1 & $\mathrm{~J}$ & $\mathrm{~K}$ & $\mathbf{L}$ \\
\hline 1 & Account & Name & country & | state_province & city & street & | street_no & Year & Month & Week & Day & Ammount \\
\hline 10254 & 87367991805 & Mauney E. Gino & USA & $C A$ & San Carlos & Dubne Court & 6030 & 1992 & 2 & 5 & 1 & 440 \\
\hline 10256 & 87375518100 & Yen E. Ann & USA & WA & Anacortes & Valley Ave. & 4148 & 1994 & 12 & 50 & 8 & 790 \\
\hline 10257 & 87378473877 & Kirby Onsby & USA & $C A$ & Redwood City & Oak Park Blwd. & 5135 & 1994 & 8 & 34 & 16 & 450 \\
\hline 10258 & 87385726571 & Wolfe Joann & Mexico & Yucatan & Merida & Sunnyvale Avenue & 8085 & 1991 & 5 & 20 & 14 & 260 \\
\hline 10261 & 87406808733 & Brinlee R. Candy & USA & $C A$ & Torrance & Vancouver Way & 1371 & 1993 & 5 & 20 & 10 & 570 \\
\hline 10262 & 87406889200 & Wells J. Robert & USA & OR & Lebanon & Lacassie Ave. & 7485 & 1991 & 12 & 49 & 4 & 720 \\
\hline 10263 & 87412865200 & Bouvier Shaneen & Canada & $\mathrm{BC}$ & Victoria & Carmel Drive & 9234 & 1993 & 3 & 11 & 9 & 60 \\
\hline 10264 & 87439274191 & Ross Fran & USA & OR & Lake Oswego & Blackridge Drive & 5603 & 1991 & 3 & 11 & 14 & 640 \\
\hline 10265 & 87448420500 & Calahoo Myreda & Canada & $\mathrm{BC}$ & N. Vancouver & La Orinda PI. & 263 & 1992 & 3 & 12 & 20 & 970 \\
\hline 10266 & 87453135848 & Ayers $V$. Mary & USA & $C A$ & Lincoln Acres & Auburn & 6885 & 1991 & 11 & 47 & 22 & 100 \\
\hline 10267 & 87458639740 & Aiello J. Ernest & USA & WA & Puyallup & Bannock Ct. & 5077 & 1991 & 5 & 22 & 26 & 860 \\
\hline
\end{tabular}




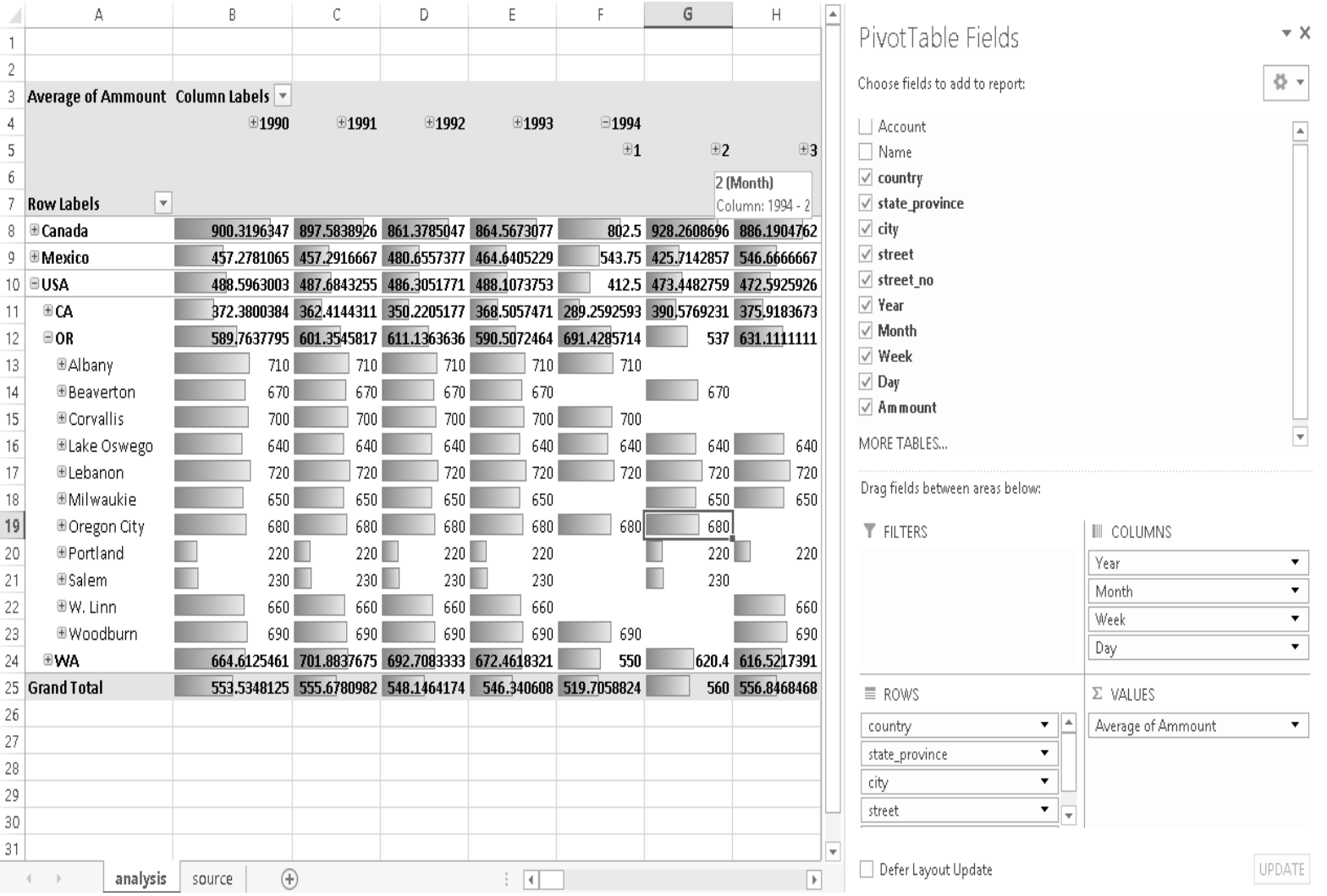

Fig. 7. Example of analytical view (pivot table \& dynamic conditional formating in Microsoft Excel) based on simple aggregations (average) on operational data (10268 records) [28]

In 2007 Watson and Wixom stated [29] that top management engagement is also a high priority factor for a useful implementation of a BI system. The senior management should have a vision for BI, they have to provide the necessary resources and insist on the use of information-based decision making processes. The use of information and analytics has to be part of the organizations culture. Watson and Wixom conceded that after its implementation the employees need to be constantly trained to use the system.

In 2008 Elbashir et al. considered [30] that the elaboration of the benefits need some time and in their early days BI systems were only viewed as tools that were used to support strategic

decision making. Nowadays enterprises use BI systems for tactical and operational process improvements like in supply chain, production and customer service.

Watson and Wixom argued that BI reduces the IT infrastructure costs and eliminates redundant data by using an extraction pro- cesses and duplicating data housed in Independent data marts across the enterprise. But they assert that one of most important benefits of using BI is to facilitate the process of finding the appropriate strategy to enter on a new market and that in a context when the companies are changing their orientation from product-centric to customer-centric. Regarding this context mentioned above, Marjanovic suggested [31] that the enterprises, especially in the service sector have to focus more on their customers and be customer orientated than product oriented.

According to Negash [32] the main tasks and benefits performed with BI are:

- creation of forecasts based on historical data, past and current performance and estimates of the direction in which the future will go;

- "What If" analysis of the impacts of changes and alternative scenarios;

- Ad hoc access to the data to answer specific, non-routine questions;

- Strategic insight.

Kocbek and Juric sustained [33] that users can 
analyse and identify trends and anomalies, execute simulations and obtain insights about business problems by using data obtained from

different business contexts.

In 2010 Tutschner stated in his book [34] some common benefits of Business Intelligence:

- Helps align the organization towards its key objectives;

- Empowers analysts and managers with a single version of the truth;

- Enables faster and fact- based decision making;

- Meets or exceeds the your customer's expectations based on factual information;

- Finds latent problems by building a picture of the information we cannot see;

- Gets instantaneous answers to next business question whereas the next business question is the question that you did not know existed until you began looking at data;

- Quickly recognizes your competitive advantages;

- Combines multiple sources of data for decision making;

- Efficiently collects and distributes essential data and statistics.

According to Watson and Wixom most progress at the moment related to the BI applications and databases are in web-based systems, real time data warehousing technologies and predictive analyses. Chaudhuri et al. confirm that real-time BI increase the customer satisfaction because the enterprises are able to react on current problems or processes immediately. They have also observed that the web-based solutions did a big progress and fulfil the same customer needs. Tutschner mentioned that predictive analytics plays an essential role in Business Intelligence which is connected with the business processes and helps to plan day-to-day operations in business. The results of predictive analytics are used to identify patterns, trends and forecast business activity flow. The accuracy of forecasts depends on the complexity of data interdependence. By increasing the number of variables, which means data from different sources the accuracy of the forecast is rising.

The technology providers are making tremendous efforts to allign their products to such features and needs. We appreciate that one major trend is worth to align with is to develop around the latest in-memory [35] databases and analytics.

In our opinion, beyond all these definitions and points of view, the practice shows that any tool representing a part of a certain type of Information System follows a cycle because it is firstly made to solve some problems (more easily) and it can and it will be progresively optimized (better) in terms of targets, models, processing, results and appellations, also influencing the whole.

\section{BI and BPM from Drucker's vision to the reality of integration difficulties}

The regretted contemporaneous theorist Peter Drucker (1959, Landmarks of Tomorrow) has been anticipated [36] a monumental leap to an age when people would generate value with their minds more than with their muscle. Drucker called that people "knowledge workers" and three decades later, he became convinced that knowledge was a more crucial economic

resource than land, labor, or financial assets, leading the "post-capitalist society." Not long before he died (2005), he declared that increasing the productivity of knowledge workers was the most important contribution management needs to make in the $21^{\text {st }}$ century.

In 2004, Negash stated [37] that the business processes which appear in the BPM literature are an unstructured input of a Business Intelligence system together with: conversations, graphics, images, movies, new items, spreadsheets, text, videos and web pages.

In 2006, IBM detailed some techniques, architectures and processes for implementing and integrating BI to achieve business performance insight. Among the specific techniques and technologies used IBM mentioned key performance indicators, alerts, management dashboards, analytic applications, application 
integration, process modeling and monitoring, and real-time business intelligence. IBM also sustained that one of the key requirements of the integration of Business Process Management and Business Intelligence is data integrity, especially with respect to the metadata (see Figure 8).

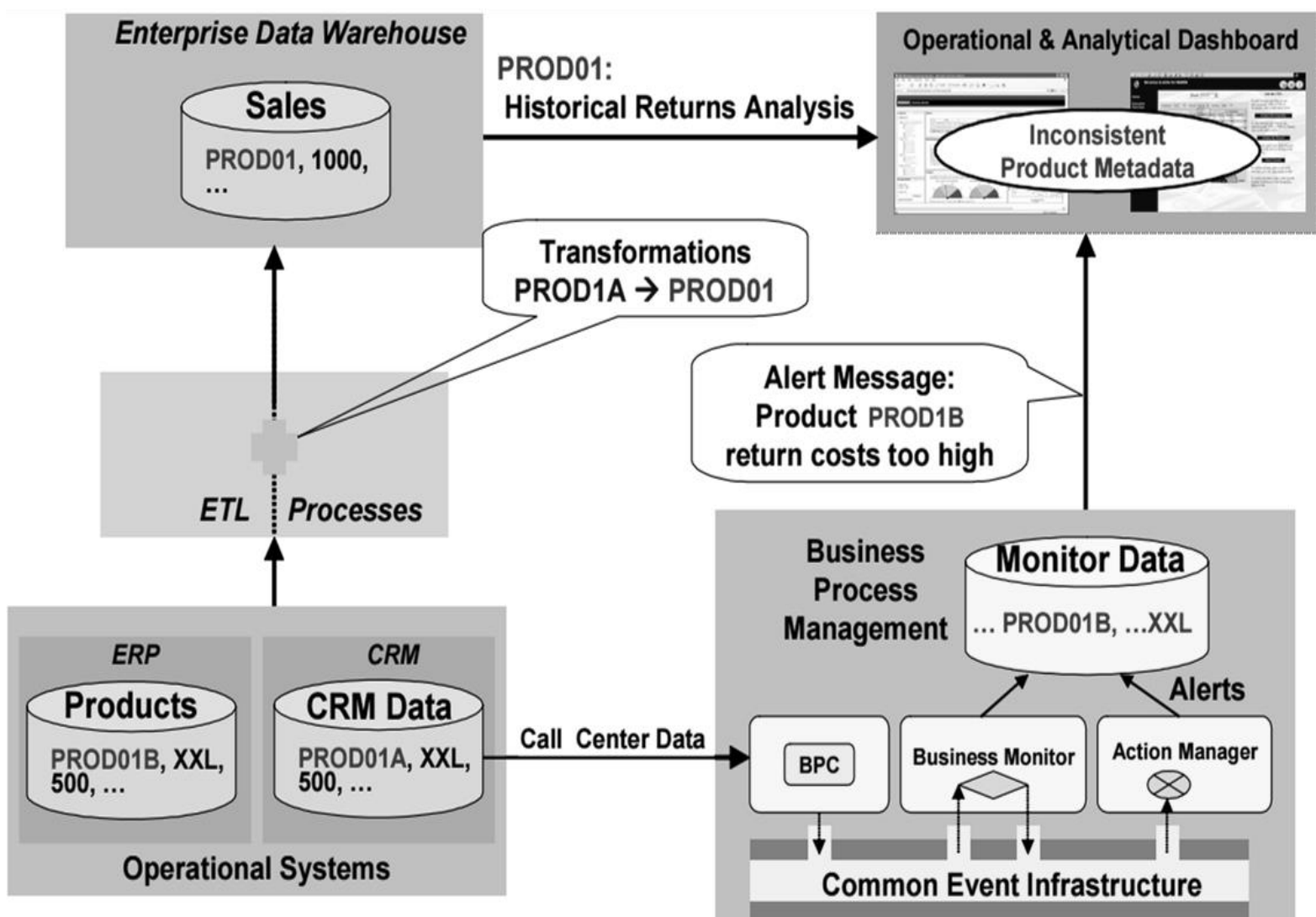

Fig. 8. Business Intelligence \& Business Process Management integration (IBM's vision) [38]

In the executive summary [39] from 2008, entitled "How organizations can use Business Intelligence and Business Process Management to optimize business processes and respond more effectively to change", IBM stated that by leveraging the capabilities of both BI and BPM, businesses can quickly drive toward successful optimization. From this point of view, the integration of both technologies allows businesses to achieve value above and beyond what can be achieved through separate use. In addition, organizations can create more effective and efficient business processes by using information and insight to enable process improvements.

By following those two sources above, we find out that at the time IBM considered SOA
(Service Oriented Architecture - currently evolved [40] into the MicroServices Architecture or MSA) as the foundation of this integration. IBM insisted that they have developed a wide range of BPM capabilities enabled by SOA that allow customers to dynamically adapt and optimize business processes to changing conditions. Being flexible, extensible, and open standards-based, SOA allows to build, deploy, and integrate services to meet evolving business process needs while leveraging existing investments. A model for continuous business performance improvement is represented by the SOA life cycle activities (see Figure 9). 


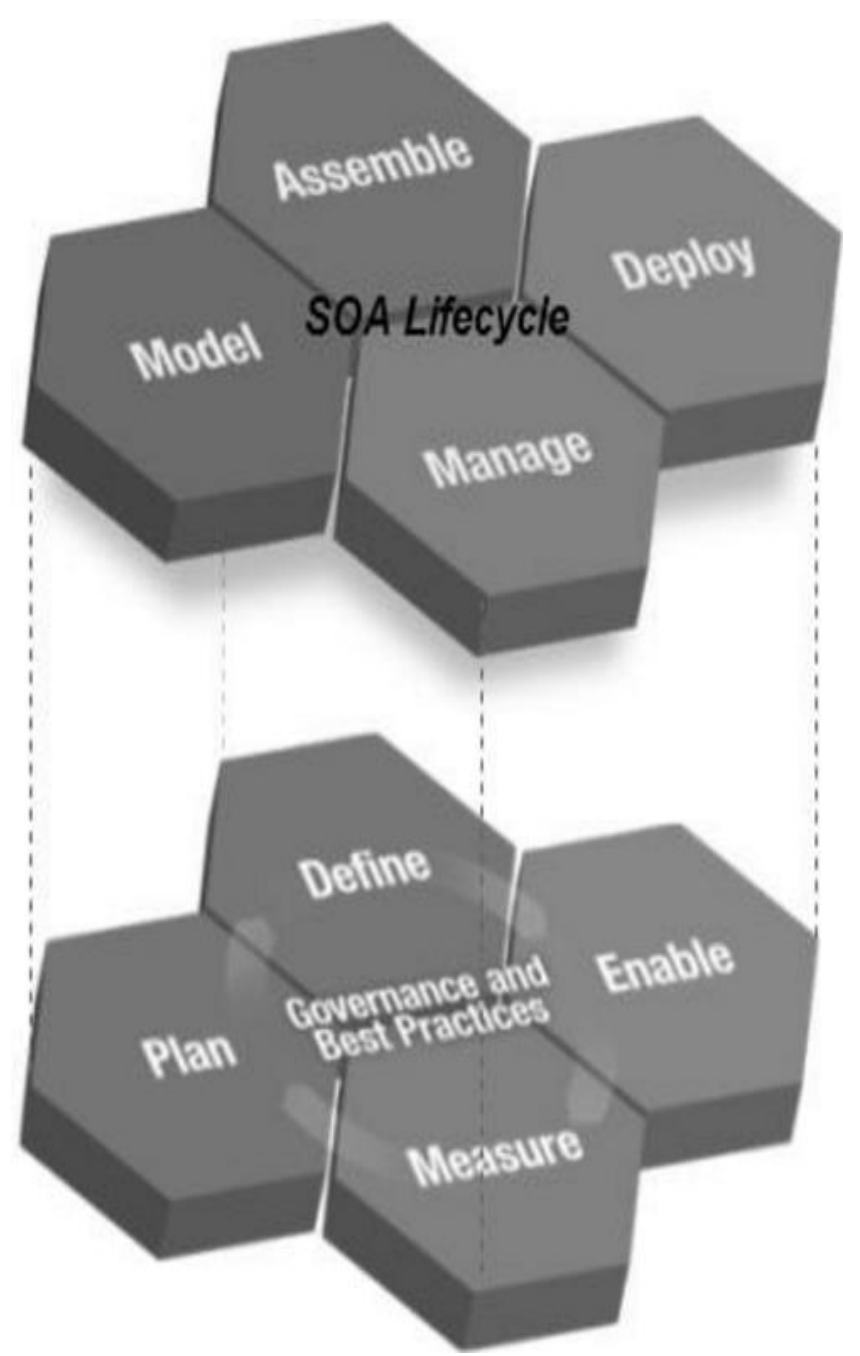

Fig. 9. The SOA life cycle and the SOA governance foundation [41]

In 2012, McKinsey [42] considered that improving effectiveness and efficiency of business

processes are the main goals for IT and nonIT Executives. This means that a Business Process Management system traditionally is focused on supporting the modelling and automation of business processes and adding BI it enables the objective of fast and cost-effective process execution. Moreover, when the amount of processes becoming automated is increasing the enterprises become more interested in managing process execution. This is the point Business Intelli- gence systems are taken seriously mainly because they are able to connect all the subsources and enable the reporting mechanism. In the same year (2012), Kerremans and Kitson (from Capgemini) claimed that adding BI analytics into the process improves and accelerates decisions, enabling better outcomes. They also considered that defining the rules is a complex process of an enterprise which means to balance sometimes with conflicting priorities in different parts of the organization and

therefore it is a high priority task and is often underestimated. 


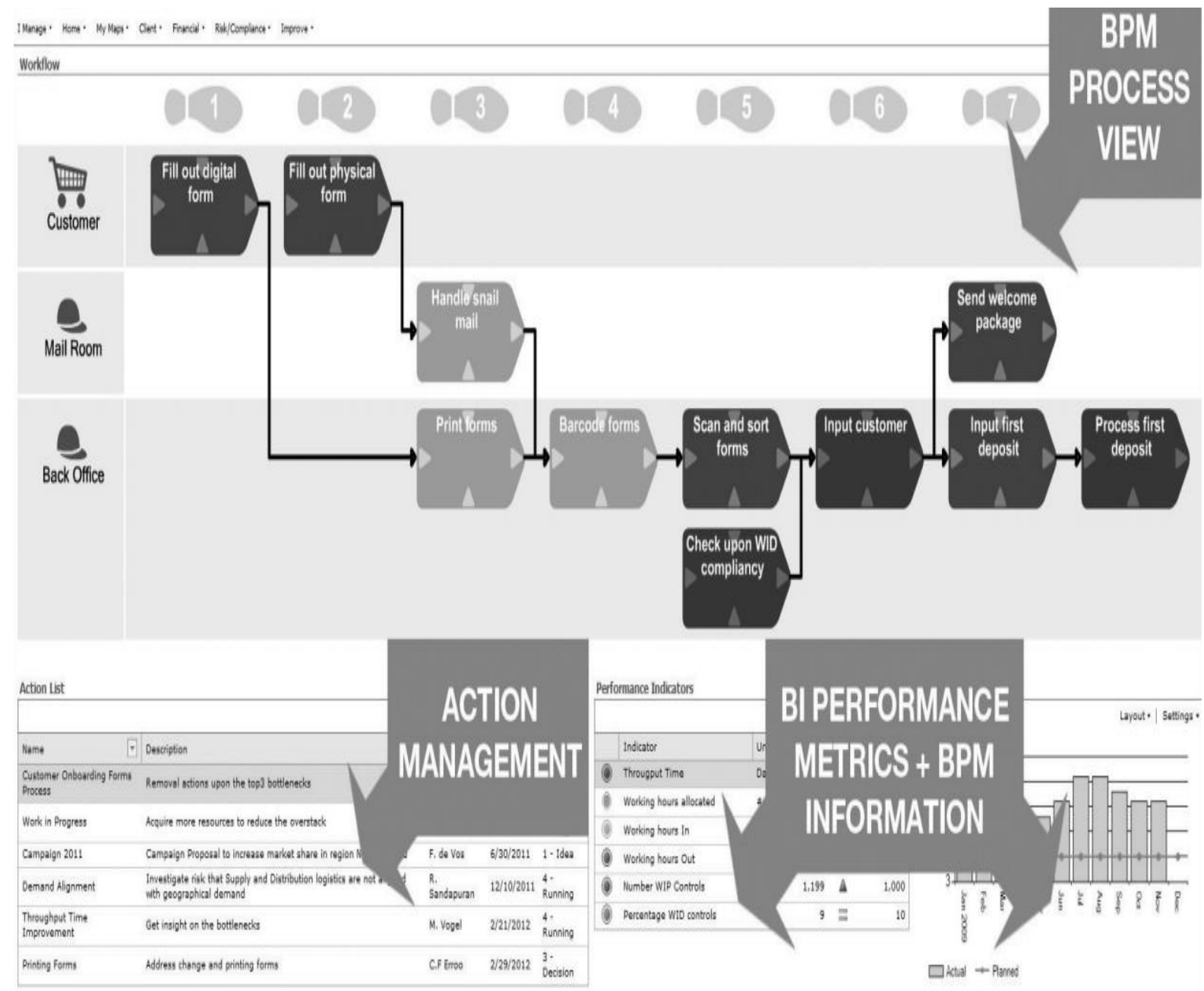

Fig. 10. Process manager cockpit (Capgemini's vision) [43]

In their vision (Figure 10), the employee following a BI based BPM approach resembles to a pilot using a so-called "process manager cockpit”.
On their official site, Pegasystems claimed that they are recognized as a leader for Intelligent Business Process Management Suites (iBPMs) in 2015 (Figure 11). 


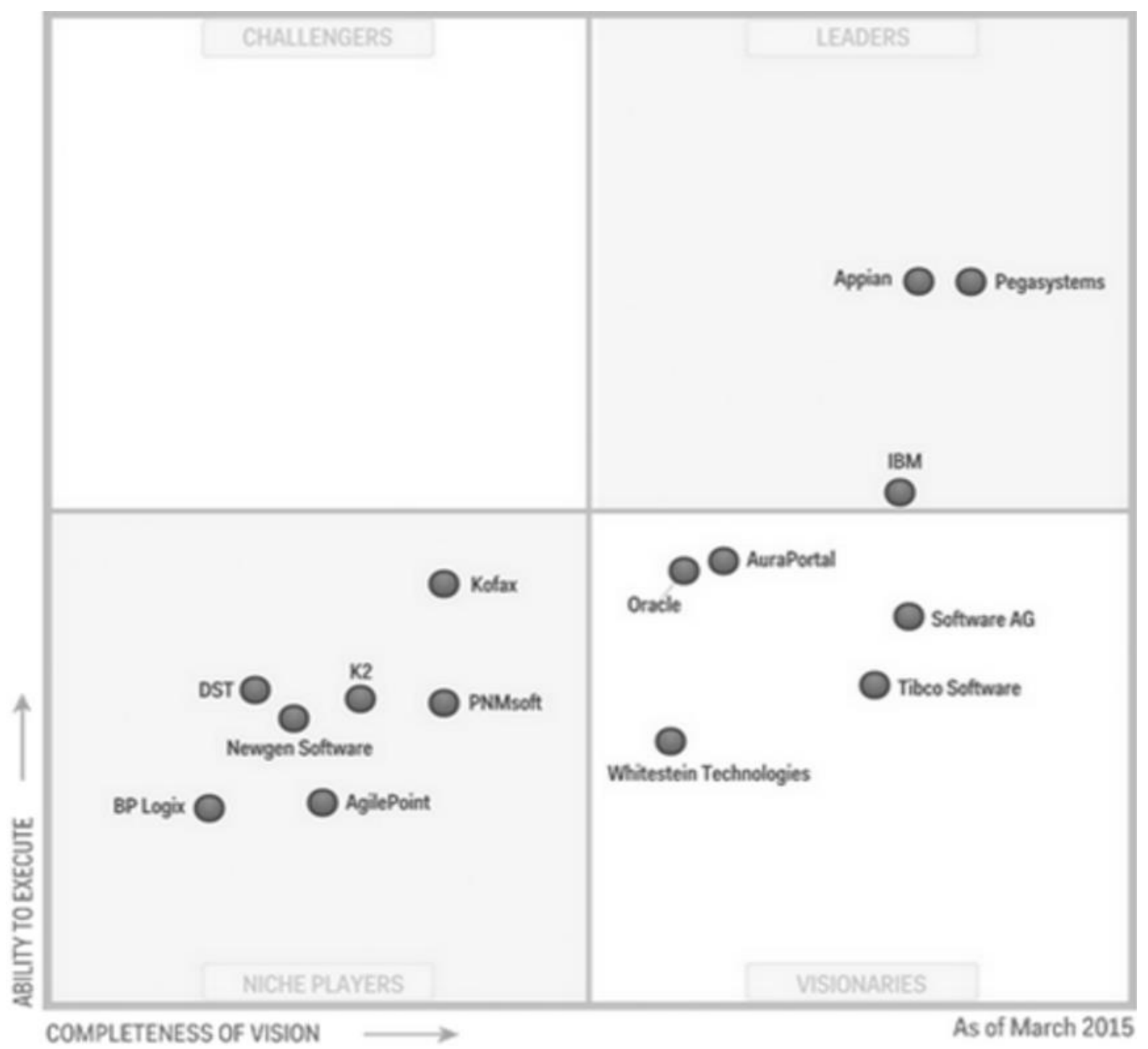

Fig. 11. The Magic Quadrant for Intelligent Business Process Management Suites (2015) [44]

They considered that being due to their advanced operational decision management capabilities, predictive analytics and IoT (Internet of Things) integration, making them a preferred implementation partner for digital business strategists at Accenture, BCG, Capgemini, and McKinsey \& Company.

\section{Conclusions}

The paper tries and we hope it manages to present solid arguments according to its provocative title involving two key concepts, namely: Business Intelligence and Business Process Management.

The approach combines definitions, theoretical ideas and some examples in order to facilitate the better understanding of the challenges reffered in the paper.
The paper does not claim completeness although it was well documented and written after testing and working with many products and technologies.

\section{Acknowledgement}

This paper was funded by the Department of Research of the Faculty of Economics and Business Administration from the "Alexandru Ioan Cuza" University of Iasi.

\section{References}

[1] www.gartner.com/it-glossary/business-intelligence-bi

[2] Sabherwal, R., Becerra-Fernandez, I., (2010), Business Intelligence: Practices, Technologies, and Management: Wiley, p.5 
[3] www.perseus.tufts.edu/hopper/ morph?l=intellegere\&la=la\#lexicon

[4] www.businessdictionary.com/ definition/business.html

[5] www.systems-thinking.org/dikw/ dikw.htm

[6] https://hbr.org/2014/10/what-peterdrucker-knew-about-2020

[7] www.conceptdraw.com/How-ToGuide/picture/PYRAMID-DIKW-

hierarchy-3d-pyrami d.png

[8] http://dssresources.com/glossary/250.php

[9] www.gartner.com/doc/1746423/businessprocess-management-bpm-key

[10] I. M. Weber, Semantic Methods for Execution-level Business Process Modeling.Modeling Support through Process Verification and Service Composition, Springer, Berlin, 2009, pp.13

[11] www.investinganswers.com/financialdictionary/ratio-analysis/efficiency-ratio2555

[12] www.cbsolution.net/techniques/ ontarget/effectiveness_vs_efficiency

[13] D. Homocianu, D. Airinei, "Business Intelligence from E -connotations to technological trends," Scientific Annals of the "Alexandru Ioan Cuza" University of Iaşi, Economic Sciences 60 (2), 2013, pp.249257 , Available at: http://saaic.feaa.uaic.ro/index.php/saaic/article/view/94/pdf_41

[14] http://dssresources.com/history/ dsshistory.html

[15] U. Sharkey, T. Acton, K. Conboy, "Decisive and Incisive - The Path of DSS", Irish Social Science PlatformConference, Dublin City University, Dublin, Sept 11-12, 2008, Available at: https://aran.library.nuigalway.ie/xmlui/bitstream/handle/10379/1605/ sharkey.2008.ISSP.pdf?sequence $=1$

[16] www.rogerclarke.com/SOS/AISHist. html

[17] http://searchcio.techtarget.com/definition/decision-support-system

[18] G. Pervan, D. Arnott, "A critical analysis of decision support systems research," Journal of Information Technology, 2005,
20: 67-87, Available at: http://espace.library.curtin.edu.au/cgi-

bin/espace.pdf?file=/2008/11/13/file_14/2 0246

[19] www.computerworld.com/article/ 2554088/business-intelligence/bi-at-age-

17.html

[20] http://dssresources.com/history/ dsshistory.html

[21] http://balancedscorecard.org/Resources/ About-the-Balanced-Scorecard

[22] C. Coronel, S. Morris, Database Systems: Design, Implementation and Management, Eleventh Edition, Cengage Learning, Stanford, 2013, pp. 568.

[23] M. Muntean, T. Surcel, "Agile BI - The future of BI," Informatica Economică, Vol. 17, No. 3, 2013, Available at: http://revistaie.ase.ro/content/67/10\%20-

$\% 20$ Muntean,\%20Surcel.pdf

[24] http://searchbusinessanalytics.techtarget.com/tutorial/How-decision-supportsystems-DSS-can-help-business-decisionmaking

[25] H. J. Watson, B. H. Wixom, "The Current State of Business Intelligence," Computer, 2007, 40(9):97

[26] S. Chaudhuri, U. Dayal, V. Narasayya, "An overview of business intelligence technology," Communications of the ACM, 2011, 54(8): 88.

[27] http://okfnlabs.org/blog/2014/01/10 /olap-introduction.html

[28] https://sites.google.com/site/supp4ie 2016bi2bpm/download/customers.xlsx

[29] H. J. Watson, B. H. Wixom, "The Current State of Business Intelligence," Computer, 2007, 40(9):96 - 99.

[30] M. Z. Elbashir, P. A. Collier, IVI. J. Davern, "Measuring the effects of business intelligence systems: The relationship between business process and organizational," International Journal of Accounting Information Systems, 9 (3), 2008, pp. 135-153.

[31] O. Marjanovic, "Looking Beyond Technology: A Framework for Business Intelligence and Business Process. Management Integration," Proceedings of BLED 2009, 2009, Available at: 
http://aisel.aisnet.org/cgi/viewcontent.cgi? article $=1024 \&$ context=bled 2009

[32] S. Negash, "Business Intelligence," Communications of the Association for Information Systems, Vol. 13, 2004, pp. 177195, Available at: http://aisel.aisnet.org/cgi/viewcontent.cgi? article $=3234 \&$ context $=$ cais

[33] A. Kocbek, M. B. Juric, "Using advanced business intelligence methods in business process management," Conference on Data Mining and Data Warehouses (SiKDD 2010), Ljubljana, Slovenia, 2010.

[34] A. Tutschner, Business Intelligence for Business Process Management, GRIN Verlag, 2010.

[35] www.oracle.com/engineered-systems/exalytics/index.html

[36] https://hbr.org/2014/10/what-peterdrucker-knew-about-2020

[37] S. Negash, "Business Intelligence," Communications of the Association for Information Systems, Vol. 13, Article 15, 2004, Available at: http://aisel.aisnet.org/cais/vol13/iss1/15

[38] www.redbooks.ibm.com/redbooks/pdfs/ sg247210.pdf
[39] ftp://public.dhe.ibm.com/software/ solutions/soa/pdfs/WSB14015-USEN-00.pdf

[40] C. Strimbei, O. Dospinescu, R.M. Strainu, A. Nistor, "Software Architectures - Present and Visions," Informatica Economică, Vol. 19, No. 4, 2015, pp. 18, Available at: http://revistaie.ase.ro/content/76/02\%20-\%20Strimbei,\%20Dospinescu,\%20Strainu,\%20Nistor.pdf

[41] www.ibm.com/developerworks/ rational/library/mar07/mcbride/

[42] www.mckinsey.com/business-functions/business-technology/our-insights/arising-role-for-it-mckinsey-global-surveyresults

[43] www.fr.capgemini.com/resource-file-access/resource/pdf/Aligning_Business_Process_Management_and_Business_Intelligence_to_Achieve_Business_Process_Excellence.pdf

[44] www.pega.com/insights/resources/2015gartner-magic-quadrant-intelligent-business-process-management-suites

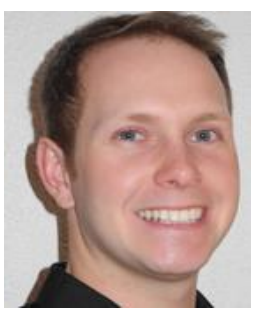

Oliver KOPF holds a Master of Science graduation diploma in the field of IT and Business Process Management from the University of Liechtenstein, Vaduz. His work focuses on Business Information Systems, Information Management, Business Process Management, Green IT and E-mobility.

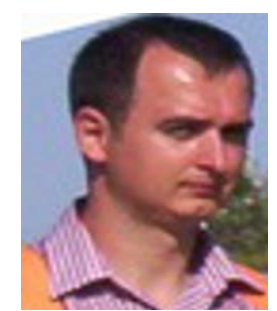

Daniel HOMOCIANU has graduated the Faculty of Economics and Business Administration (FEAA), Alexandru Ioan Cuza University of Iasi (UAIC) in 2002. He holds a PhD diploma in Cybernetics and Economic Statistics (2009) and he is currently a researcher within the Department for Research at FEAA UAIC. He is author/co-author of 8 books and more than 60 scientific articles in the field of Business Information Systems. 